\title{
Olhares e reflexões contemporâneas sobre o triângulo sociedade-educação-tecnologias e suas influências no ensino das ciências
}

Carla Morais

João Paival

\section{Resumo}

Quando se combinam termos como sociedade, educação etecnologias, parece destacar-se a ideia de que as tecnologias têm sido associadas a algumas das mais expressivas mudanças ocorridas na sociedade do século XX e início do século XXI, e têm sido relatadas como capazes de influenciar aspetos diversos e significativos da realidade social, a ponto de alguns autores dizerem que estamos perante uma nova forma de organização da sociedade e do sistema econômico, à qual o sistema educativo deveria procurar corresponder, adequando-se. Neste artigo, apresentam-se algumas perspetivas e olhares que julgamos úteis para alavancar uma reflexão sustentada e projetiva sobre o passado, o presente e o futuro das inter-relações entre as esferas social, educativa e tecnológica e as possíveis influências daí decorrentes para o ensino das ciências. Assim, de forma mais descritiva, importa referir que este artigo é constituído por cinco tópicos que julgamos relevantes para consubstanciar a reflexão sobre a temática em apreço. Começando por apresentar algumas considerações sobre a sociedade da informação, a metáfora da rede e o potencial coletivo, segue-se um enfoque nas tecnologias e na sua relação com as "escolas que aprendem". Na medida em que o letramento digital não se esgota na competência tecnológica, a instituição escolar - e os seus agentes - pode assumir um papel de mediação entre os desafios da sociedade do conhecimento e as novas gerações. Nesse contexto de interdependências múltiplas, termina-se o artigo com algumas reflexões sobre a educação em ciência, o ensino das ciências e o letramento científico na sociedade da informação.

\section{Palavras-chave}

Ensino das ciências - Sociedade tecnológica - Educação.

I- Universidade do Porto, Porto, Portugal Contatos: cmorais@fc.up.pt; jcpaiva@fc.up.pt 


\title{
Perspectives and contemporary reflections on the triangle education-technology-society and its influence on science teaching
}

\author{
Carla Morais \\ João Paiva'
}

\begin{abstract}
When we talk about society, education and technology, it becomes clear how technology has been the source of the most expressive changes that occurred in the society of the 20th and early 21st centuries' society. Technology has been pointed out as responsible for transforming several significant aspects of social reality to such an extent that some authors argue that we are facing new forms of organization of the economic system and of society, which the educational system should seek to match and accommodate. In this article, we present different perspectives which we believe can be successful in promoting a sustained and projective reflection on the past, the present and the future of the interrelationships in social, educational and technological spheres and the possible effects on science teaching that they entail. The article addresses five topics deemed relevant to substantiate the reflection on the subject under consideration. We first present some thoughts about the information society, the network metaphor and the collective potential. We continue with a focus on technology and its relation with the "schools that learn". We then argue that digital literacy goes far beyond technological competence and stress how schooland its agents - can play a mediating role between the challenges of the Knowledge Society and new generations. In this context of multiple interlinked dependencies, the article ends with reflections on science education, science teaching and scientific literacy in the information society.
\end{abstract}

\section{Keywords}

Science teaching - Technological society - Education.

I- Universidade do Porto, Porto, Portugal

Contatos: cmorais@fc.up.pt;

jcpaiva@fc.up.pt 


\section{A sociedade da informação, a metáfora da rede e 0 potencial coletivo}

0 advento da sociedade da informação é muitas vezes apresentado como um acontecimento natural, resultante das tendências modernizadoras e inovadoras nas sociedades ocidentais, cuja alavanca fundamental são as tecnologias da informação e comunicação (TIC).

Como nos adverte Almeida (2000), a expressão sociedade de informação, à semelhança do conceito de globalização, surge recorrentemente nos discursos científicos e nos discursos quotidianos para explicar os fenômenos sociais em curso, às vezes, sem adquirir um significado exato e abrigando conceções reducionistas de acordo com as quais a tecnologia per se é capaz de transformar as sociedades.

$\mathrm{Na}$ generalidade dos discursos e das análises, a Sociedade da Informação é descrita como um desafio em direção ao qual é suposto que todos os cidadãos se mobilizem. Por essa razão, os teóricos da Sociedade da Informação invocam as escolas e os sistemas educativos como parte fundamental do processo de mudança ambicionado, i.e., "levar os indivíduos a perceber a dimensão das mutações em curso e as suas consequências" (AFONSO; ANTUNES, 2001, p. 7). Se é verdade que a instituição escolar repercute as tensões e dilemas atuais, qual será o seu papel - e o papel dos seus agentes - na transição de uma sociedade industrial para uma sociedade do conhecimento?

No dealbar da sociedade da informação, a metáfora da máquina - que nasceu no final do século XVIII e se desenvolveu durante a sociedade industrial - já não tem sentido como modelo inspirador da educação e da aprendizagem. Tal como nos indica Figueiredo (2002), a metáfora da rede parece agora perfilar-se para nos inspirar. No passado, a metáfora da máquina valorizava o individualismo, a ausência de contextos, a rotina, a mecanização, a passividade. Atualmente, a metáfora da rede valoriza a comunidade, a interação, os contextos, os processos orgânicos, a geometria variável, a complexidade, o fluxo e a mudança. Num ambiente mecanicista, o "aluno-peça-de-máquina" aprendia isolado, inserido numa multidão de outros “alunos-peças-de-máquina”, igualmente isolados. Embora se amontoasse, com os seus iguais, na sala de aula, construía a sua própria aprendizagem quase sempre em solidão e em solidão era avaliado. Ressalve-se, no entanto, que, a despeito da influência predominante de modelos de aprendizagem S-R, houve sempre concepções concorrentes. ${ }^{1}$

Voltando aos ambientes em rede, os "alunos-nós-de-rede", membros de comunidades, sentem que a construção do seu conhecimento é uma aventura coletiva - uma aventura onde constroem os seus saberes, mas onde contribuem, também, para a construção dos saberes dos outros (FIGUEIRED0, 2002).

A evolução rápida das TIC e a emergência da sociedade da informação têm estimulado reflexões várias, a ponto de se tornar notória, segundo alguns autores, a emergência de um novo modelo de concepção das sociedades contemporâneas. São abundantes os enunciados sobre uma nova era resultante da conjugação da informática com as telecomunicações, destacando e sublinhando a ideia de que a prosperidade futura dependerá dos processos de manipulação, de transmissão, de armazenamento e de controle da informação. A relação, porém, entre a tecnologia e a sociedade não é unívoca. Como nos diz Castells (1999, p. 25), "a tecnologia não determina a sociedade (...) a tecnologia é a sociedade, e a sociedade não pode ser entendida ou representada sem as suas ferramentas tecnológicas." Recusando, assim, qualquer espécie de determinismo tecnológico, tanto Castells (2004) como Levy (1997) discutem

1- Abreu (1999), por exemplo, discute detalhadamente as hipóteses concorrentes de tarefa aberta e tarefa fechada, mostrando como diacronicamente houve alternativas aos modelos conexionistas e comportamentalistas. Para além disso, a máquina (o programa que sinaliza o erro e o sucesso) desempenha um papel fulcral nas derivações pedagógicas do comportamentalismo. Assim, fica claro que a tecnologia em si mesma não é mais favorável a modelos construtivistas do que a outros, refletindo, isso sim, as conceções pedagógicas que estão na sua origem e que the sucedem na prática. 
o papel do indivíduo integrante dessa teia enquanto agente disseminador da informação.

Para Lévy (1998), os “vencedores” de hoje são os que melhor conseguirem mobilizar e coordenar os saberes, as inteligências, as imaginações e as vontades. Isto porque, segundo esse autor, quanto melhor circular a informação, mais rapidamente serão avaliadas as decisões, mais se desenvolverão as capacidades de iniciativa, de inovação e de reorganização e mais competitivas serão as empresas, as regiões, os países etc. Sugere ainda que deverá ser incentivado o desenvolvimento de processos que contribuam para fazer emergir a inteligência e a imaginação coletiva. Comungando dessa perspetiva, Matta (2006) refere que, no seio da sociedade atual, é necessário potencializar a atividade de criação, de iniciativa, de capacidade para enfrentar o desconhecido e o novo, com versatilidade e com trabalho coletivo. A relação desejada para uma escola, nesse ambiente, tende a ser a de grupos de indivíduos que interatuem mutuamente na exploração e na vivência de experiências relevantes, atendendo aos objetivos e às tarefas a realizar, procurando utilizar as TIC como mediadoras de parte importante da sua aprendizagem. Negroponte (1996) considera que, graças à chegada da informática, o aprender fazendo e o construtivismo tornaram-se abordagens quase obrigatórias. Para William Doll Jr. (1998), todo o contexto atual tornou mais compreensíveis, aplicáveis e desejadas as abordagens pedagógicas ativas, construtivistas e experimentais como formas privilegiadas de construção do conhecimento, ao mesmo tempo que a interação social, o trabalho coletivo e as relações do sujeito com o ambiente são considerados fatores essenciais para uma aprendizagem autêntica voltada para a realidade do contexto vivido. Também Sousa e Fino (2008) recordam que, há já muito tempo, os construtivistas vêm reclamando a natureza ativa da cognição. Essa ideia, não contradizendo a pertinência da transmissão de informação, descarta a hipótese da transmissão de conhecimento, uma vez que o conhecimento é algo pessoal, construído pelo sujeito. Por outro lado, onde o construtivismo indica o sujeito como construtor ativo e argumenta contra modelos passivos de aprendizagem, um ponto de vista construcionista avança um pouco mais, ao enfatizar as construções particulares do indivíduo, que são externas e partilhadas. Sobre essa ampliação do conceito de construtivismo, escreve Papert (1990, p.3):
Nós entendemos "construcionismo" como [uma concepção] integrando, mas indo para além do que Piaget chamaria de "construtivismo". A palavra com um $t$ expressa a teoria de que o conhecimento é construído pelo aprendiz e não fornecido pelo professor. A palavra com um c expressa ainda a ideia de que isto acontece de forma particularmente feliz quando o aprendiz é envolvido na construção de algo exterior ou pelo menos partilhável... um castelo de areia, uma máquina, um programa de computador, um livro. Isso conduz-nos a um modelo baseado num ciclo de internalização do que está fora, depois externalização do que está dentro e assim por diante.

De certo modo, Papert (1990) realça a possibilidade de refletir sobre as vias pedagógicas que se abrem a partir da tecnologia. Cada tecnologia expressa (exterioriza) um projeto, cuja intencionalidade poderá ser revertida (apropriada) pelo aprendiz e expandida, através da partilha significativa com os outros.

Papert (1991, 1993) defende, ainda, que são pressupostos da construção do conhecimento: a) a aprendizagem situada, profundamente mergulhada, e parte do contexto em que decorre; b) a negociação social do conhecimento, que é o processo pelo qual os aprendizes formam e testam as suas construções em diálogo com outros indivíduos e com a sociedade em geral; e c) a colaboração, que é o elemento indispensável para que o conhecimento possa ser negociado e testado. Essas posições encontram eco simultaneamente no construtivismo e na teoria 
de Vygotsky (1978) e dão ânimo não apenas à reivindicação de métodos ativos de educação, mas sobretudo ao papel essencial da interação (vertical e horizontal) como suporte essencial dos processos de cognição. No entanto, será que a tecnologia pode configurar-se como "uma das chaves da concretização de um novo paradigma educativo, capaz de fazer incrementar os vínculos entre os alunos e a comunidade, enfatizar a descoberta e a aprendizagem, e de fazer caducar a distinção entre aprender dentro e fora da escola" (SOUSA; FINO, 2008, p. 25)?

Ora, Paiva et al. (2010) defendem que a mudança de paradigma de uma escola mecanicista, que encara o saber como fragmentado e estanque, para uma escola interdependente e global ou, segundo Senge (1990), de "pensamento sistêmico", pode ser mediada através da utilização das TIC. As ferramentas tecnológicas disponíveis poderão potenciar a desejável mudança pedagógica nas práticas e nos agentes educativos, dentro e fora da escola.

\section{As tecnologias e as "escolas que aprendem"}

Senge trouxe da reflexão sociológica e econômica novos e grandes desafios para as "escolas que aprendem". A esse autor se deve a difusão do conceito learning organizations (SENGE, 1990, 2002), que se concretiza na recomendação da prática das suas cinco disciplinas.

As disciplinas são um conjunto de práticas de aprendizagem, através das quais um indivíduo se modifica, desenvolvendo novas competências, construindo conhecimentos, vivenciando experiências e adquirindo progressivamente diferentes níveis de consciência de si. Quando desenvolvidas em conjunto, as disciplinas podem ter um impacto significativo e objetivo sobre o desempenho de cada indivíduo.

0 Quadro 1 sintetiza algumas das principais ideias que globalmente caracterizam cada uma das cinco disciplinas propostas por Peter Senge (1990, 1995, 1998, 1999, 2000, 2002, 2005).

Quadro 1 - As cinco disciplinas de Senge

\begin{tabular}{|c|c|}
\hline Disciplina & Descrição \\
\hline $\begin{array}{l}\text { Primeira disciplina - Mestria Pessoal } \\
\text { ou Domínio Pessoal }\end{array}$ & $\begin{array}{l}\text { Disciplina que se relaciona com a tomada de consciência e desenvolvimento das nossas capacidades } \\
\text { para obter aquilo que desejamos para nós. Esta atitude de aprendizagem é um misto de auto e } \\
\text { heteroconhecimento que pressupõe uma atitude reflexiva, de (re)conhecimento dos limites pessoais, } \\
\text { das virtudes e desvirtudes de forma a compreender, tanto quanto possível, o todo que somos. }\end{array}$ \\
\hline $\begin{array}{l}\text { Segunda disciplina - Modelos } \\
\text { Mentais }\end{array}$ & $\begin{array}{l}\text { Disciplina que consiste em refletir, esclarecer continuamente e melhorar a imagem que cada um tem } \\
\text { do mundo, a fim de verificar como moldar atos e decisões. Senge essencialmente propõe que tomemos } \\
\text { consciência da nossa mundividência, desenvolvendo aptidões de investigação e reflexão, visando a } \\
\text { alcançar a consciência das atitudes e percepções, tanto nossas como dos outros à nossa volta. }\end{array}$ \\
\hline Terceira disciplina - Visão Partilhada & $\begin{array}{l}\text { Disciplina que se foca no estabelecimento de objetivos comuns, a partir de uma visão pessoal, que leva } \\
\text { ao fenômeno muito importante da criação conjunta e do sentido de comprometimento com o grupo. }\end{array}$ \\
\hline $\begin{array}{l}\text { Quarta disciplina - Aprendizagem } \\
\text { em Equipe }\end{array}$ & $\begin{array}{l}\text { Disciplina coletiva, que procura transformar as aptidões coletivas ligadas ao pensamento e à } \\
\text { comunicação, de maneira que grupos de pessoas possam desenvolver inteligência e capacidades } \\
\text { maiores do que a soma dos talentos individuais. }\end{array}$ \\
\hline $\begin{array}{l}\text { Quinta disciplina - Pensamento } \\
\text { Sistémico }\end{array}$ & $\begin{array}{l}\text { Disciplina que se foca no propósito de perceber o mundo como um conjunto integrado de } \\
\text { acontecimentos e relações. Nesse sentido, é muito importante conhecer bem o todo antes de nele } \\
\text { fazer qualquer intervenção, pois uma alteração num sistema afeta, necessariamente, a sua globalidade } \\
\text { e as suas vizinhanças. } 0 \text { pensamento sistémico opõe-se ao pensamento estático e tem qualidades } \\
\text { únicas que o tornam uma ferramenta fundamental para modelar sistemas complexos, como são } \\
\text { aqueles que gravitam em torno da problemática da educação. }\end{array}$ \\
\hline
\end{tabular}

Fonte: Senge (1990, 1995, 1998, 1999, 2000, 2002, 2005)

Tal como referem Paiva et al. (2010), entre as cinco disciplinas de Peter Senge, sobressai, por um lado, a do Pensamento Sistémico, que vem reforçar a atitude de modelagem sistêmica. Por outro lado, existem duas disciplinas que são colaborativas - Visão Partilhada e Aprendizagem 
em Equipe - reforçando a importância dos aspetos colaborativos, muitas vezes esquecidos nas dinâmicas de ensino e de aprendizagem. As duas disciplinas restantes de Senge - Mestria Pessoal e Modelos Mentais - remetem para uma necessidade de reflexão e sentido crítico e possuem uma natureza mais pessoal.

Como podemos constatar, essa abordagem restitui à instituição escolar a possibilidade de reinvenção, participando da construção do projeto social, de acordo com as necessidades e as exigências decorrentes da sociedade atual, a partir do ensaio e da reflexão sobre a prática, como qualquer aprendente. Essa concepção oferece a via para um enquadramento legítimo das TIC in media res. Com efeito, as disciplinas constituem uma senda de autoconhecimento em nível pessoal ou institucional, mediado pela comunicação e orientado para a mudança.

Não obstante esse fato, importa destacar que, embora nos entusiasme a modernidade que as TIC nos oferecem, somos, frequentemente, incapazes de fazer com elas mais do que fazíamos sem elas. Poderíamos apropriadamente lembrar as palavras de Thoreau (1954/1995):

As nossas invenções são tidas como brinquedos bonitos, que nos distraem das coisas sérias. Não são senão meios melhorados para um fim por melhorar, um fim a que não era já senão fácil chegar; como os caminhos-de-ferro que levam a Boston ou Nova Iorque. Nós estamos desejosos de construir um telégrafo magnético entre o Maine e o Texas; mas, talvez, o Maine e o Texas não tenham nada de importante para comunicar.

\section{Aprender a tecnologia e aprender com a tecnologia}

Muñoz-Repiso (2003) defende a importância do sistema educativo proporcionar um primeiro acesso aos equipamentos e programas informáticos, de modo que os alunos aprendam a usar a tecnologia. Contudo, depois é crucial que essa fase de aprendizagem "básica" da tecnologia seja precursora da fase de "utilizar para aprender", isto é, é crucial que os alunos tenham oportunidades de utilizar a tecnologia como uma ferramenta que lhes permita aprender (Figura 1).

Por outro lado, Jonassen (2007), sem defender que o conhecimento sobre computadores é irrelevante, e baseado numa forte convicção de que é um erro pensar que os alunos ficarão aptos a usar um computador se memorizarem os seus componentes e funcionalidades, acredita que um importante caminho a percorrer deverá, antes de mais, passar por compreender que as ferramentas informáticas só têm utilidade se apoiarem objetivos de aprendizagem significativa. Também nesse sentido, Papert (1980) defende que o papel do professor deverá consistir, fundamentalmente, em saturar o ambiente de aprendizagem com os nutrientes cognitivos a partir dos quais os alunos constroem o seu conhecimento. Defende ainda que devem ser proporcionadas a esses mesmos alunos as ferramentas que lhes possibilitem uma exploração completa dos nutrientes cognitivos existentes.

Figura 1 - Utilização da tecnologia na sociedade da informação

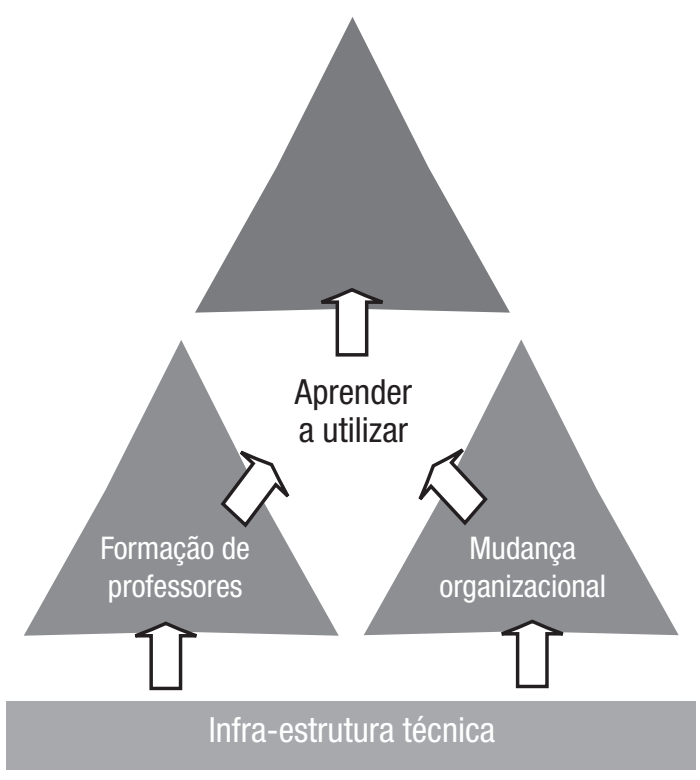

Fonte: Adaptado de Muñoz-Repiso (2003) 
Com efeito, o aparelhamento tecnológico das escolas pode contribuir para a superação da defasagem digital entre comunidades socioeconomicamente mais favorecidas e as comunidades mais desfavorecidas (HOHLFELD; RITZHAUPT; BARON, 2010). Adicionalmente, a integração das TIC no quotidiano acadêmico pode promover a comunicação entre as famílias e as escolas (LEWIN; LUCKIN, 2010).

Contudo, na prática, os professores, mesmo os mais entusiastas, sentem dificuldade na articulação do "como" e do "para quê" usar as TIC em contexto educativo (HENNESSY; RUTHVEN; BRINDLEY, 2005). Por outras palavras, o processo de integração pedagógica das TIC revela-se muito exigente para o professor, porque lhe compete organizar e estruturar as atividades por níveis crescentes de complexidade (POSTHOLM, 2006).

Essa evidência sugere a necessidade de clarificar o potencial das TIC para a criação de oportunidades de aprendizagem que permitam a construção e o desenvolvimento sustentado de saberes escolares, tendo em conta as especificidades e os objetivos a alcançar em cada área curricular. Nesse sentido, e considerando que a utilização das TIC, enquanto formação transdisciplinar de caráter instrumental, não se reduz à aquisição de saberes na área das tecnologias, mas que (sem os dispensar) os integra num processo de formação global, tal como nos alerta Roldão (1999, p. 17), é crucial, do ponto de vista da teorização curricular, repensar a utilização das TIC no sentido de

[...] se criarem quadros de referência cultural e científica, de integração de conhecimentos e domínio de capacidades, de construção de competências que viabilizem processos realistas de formação ao longo da vida e não reduzam essa formação a uma retórica bem-intencionada.

Nesse contexto, também no relatório ICT ande-learning infurthereducation:management, learning and improvement, publicado pela British Educational Communications and Technology Agency (BECTA, 2006, p. 3) pode-se ler: "a necessidade de desenvolver no staff competências combinadas com entusiasmo pelo ensino à distância é vista como um elemento essencial para incorporar as TIC e o ensino à distância em qualquer área do currículo."

0 "espaço" de flexibilidade permitido no currículo, em conjunto com os níveis de confiança e de competência dos professores, parece, pois, defınir o âmbito e a abrangência da inovação das TIC em contextos educativos (BARAJAS et al., 2002). Também Miranda (2007) afırma que a integração benéfica das TIC depende das crenças e práticas exploratórias das possibilidades tecnológicas pelos professores para: a) abordar a informação; b) apoiar os alunos no processo de construção de conhecimento; e c) integrá-las no currículo através de projetos criativos.

Ainda segundo Miranda (2007), através desses novos sistemas de tratamento e representação da informação e de comunicação, os professores podem desenvolver com os alunos atividades que favoreçam a aquisição de conhecimentos disciplinares significativos. 0 Quadro 2 apresenta-nos as principais características do processo de aprendizagem.

Se parece inegável que a escola, como hoje a entendemos, necessita sofrer mudanças radicais, é igualmente verdade que essas mudanças terão forçosamente de ocorrer com e pelos professores. Tal como nos alerta Nóvoa (2007), a integração das novas tecnologias na educação mostra-se irremediavelmente associada à necessidade de reforço da profissionalização docente e de uma (re)organização marcada das dinâmicas escolares. Ensinar hoje deve ser visto como um processo flexível, em conteúdos, metodologias, outcomes e mesmo nos vetores tempo e espaço, assentando assim em processos mais abertos de pesquisa, interação e colaboração (PEDRO et al., 2010). 
Quadro 2 - As características do processo de aprendizagem

\begin{tabular}{|c|c|}
\hline Característica & Descrição \\
\hline (Re)construtivo & $\begin{array}{l}\text { Os alunos constroem os novos conhecimentos com base nas estruturas e representações já adquiridas sobre os } \\
\text { fenômenos em estudo. }\end{array}$ \\
\hline Cumulativo & Implica que os novos conhecimentos são adquiridos com base nas aprendizagens realizadas anteriormente. \\
\hline Autorregulado & $\begin{array}{l}\text { Os professores devem procurar apoiar os alunos para desenvolver estratégias de aprendizagem de modo a adquirirem } \\
\text { hábitos de estudo e de trabalho intelectual, e ainda padrões de correção do seu próprio trabalho, de modo a } \\
\text { progressivamente se irem autonomizando da tutela do professor. }\end{array}$ \\
\hline Intencional & $\begin{array}{l}\text { Implica que o conhecimento, por parte dos alunos, das finalidades ou metas a atingir em cada situação de } \\
\text { aprendizagem, facilita o processo de construção de conhecimento, pois imprime-lhe uma intencionalidade e direção. }\end{array}$ \\
\hline Situado & $\begin{array}{l}0 \text { sentido da aprendizagem advém do contexto onde foi realizada. São os contextos que facilitam ou, pelo contrário, } \\
\text { dificultam a aplicação dos conhecimentos. }\end{array}$ \\
\hline Colaborativo & Ocorre em contextos de práticas sociais que implicam a colaboração entre iguais e destes com os adultos. \\
\hline
\end{tabular}

Fonte: Miranda (2007)

\section{Novos desafios, novas inspiraçōes, novos alunos e professores}

0 desafio atual passa por conciliar a extensão da informação, a variedade das fontes de acesso, com o aprofundamento da sua compreensão, em espaços menos engessados (MORAN, 2009).

Predominam os discursos que sustentam que um novo tipo de realidade fez eclodir um novo tipo de alunos, exigindo um novo tipo de escola, e impõe novas competências aos seus professores (DAVIS; ROBLYER, 2005). Levin e Arafeh (2002) sugeriram inclusive que existia um fosso digital entre a escola e o lar. Esses alunos são aqueles que nasceram num mundo saturado de new media, que sempre viram as suas vidas imersas em tecnologia (VANSLYKE, 2003). São os que não vivem sem telefones celulares. São aqueles que têm (ou ambicionam ter) iPods, TV no quarto, Playstations, Wiis etc. São quem não sai com os pais sem levar seu DS ou PSP. Esses alunos são os que conhecem o Twitter e se conhecem no Facebook (PEDRO et al., 2010). Essa geração aprende as cores, os números, as letras, baixa arquivos, instala programas, mistura músicas, resolve problemas de ligação, edifica vilas e gere sistemas econômicos (KNOWLTON, 2007) antes da entrada para a escola. "Os jovens desta geração estão habituados a receber informação realmente depressa. Eles gostam de uma dinâmica de processos em paralelo e multitarefas. Eles preferem os seus gráficos antes do seu texto, em vez do contrário. Eles preferem o acesso aleatório (como o hipertexto)" (VANSLYKE, 2003).

Porém, esses discursos pervasivos e dominantes, como realçam Bennett, Matton e Kervin (2008), nem sempre são sustentados empiricamente $^{2}$. Kolikant (2012), por exemplo, reeencontra entre os estudantes a representação de um ensino centrado no professor e que identifica a aprendizagem à memorização. Contrariamente ao que seria de esperar de acordo com os discursos hegemônicos, os estudantes não utilizavam a Internet senão para realizar as tarefas acadêmicas mais simples; não a usavam para a estudar para os exames e não desejavam utilizá-la de forma mais intensa, considerando-se menos competentes do ponto de vista acadêmico do que as gerações anteriores.

\section{Educação em ciência, ensino das ciências e letramento científico na sociedade da informação}

Reconhecendo as mudanças decorrentes da transição de uma sociedade industrial para uma sociedade da informação, acredita-se que

2- Para uma revisão teórica e operacionalização do conceito de nativos digitais, veja-se International Telecommunication Union (2013). 
ser capaz de usar as TIC é uma das competências-chave para o século XXI. Por outro lado, defendendo-se que a educação dos indivíduos em ciências, bem como em qualquer outro domínio, deverá ser um processo continuado ao longo de toda a vida, o ensino formal deverá ter como orientação de base o de preparar os indivíduos em saberes básicos e competências que lhes permitam continuar o processo de aprendizagem.

Segundo Wan (2012), o conceito de letramento digital estrutura-se em três dimensões: a) dimensão cognitiva: b) dimensão socioemocional; c) dimensão técnica ${ }^{3}$. De acordo com essa concepção, é possivel e necessário ensinar letramento digital às gerações mais jovens, uma vez que o domínio técnico se revela frequentemente insuficiente para fazer face aos desafios da sociedade moderna.

Num sentido semelhante, a letramento científico, segundo Chassot (2000), deve dar prioridade à formação de cidadãos cientificamente cultos, capazes de participar ativa e responsavelmente em sociedades que se querem abertas e democráticas. Assim, o sentido da expressão "cientificamente culto" vai ao encontro do expresso por Hodson (1998), ou seja, um conceito multidimensional envolvendo simultaneamente três dimensões: a) aprender ciência: relacionada com a aquisição e o desenvolvimento de conhecimento conceitual; b) aprender sobre ciência: compreensão da natureza e métodos da ciência, evolução e história do seu desenvolvimento, bem como uma atitude de abertura e interesse pelas relações complexas entre ciência, tecnologia e sociedade; e c) aprender a fazer ciência: dimensão relacionada com as competências para desenvolver percursos de pesquisa e resolução de problemas. Como referem Cachapuz et al. (2004), importa atender ao fato de que o aprofundamento de tais dimensões não é naturalmente o mesmo quando se trata da formação de futuros cientistas ou da perspetiva da educação para a cidadania. De igual modo, e

3- Para uma revisão do conceito de letramento digital, veja-se Bawden (2008). no âmbito do ensino formal, o aprofundamento não é naturalmente o mesmo em diferentes níveis de ensino.

Ora, as últimas décadas foram particularmente ricas no aumento da consciência social sobre a importância das competências de letramento dos indivíduos, em nível pessoal e socioeconómico das nações, o que se traduziu no incremento da necessidade de precisar o(s) signifıcado(s) do termo e de definir padrões de letramento com aceitação internacional (MARTINS et al., 2004).

Nesse contexto, parece-nos oportuna uma referência ao PISA (OCDE, 2003), que define o letramento científico em termos dos conhecimentos científicos e da capacidade de o indivíduo utilizar esses mesmos conhecimentos para identificar questões para as quais a ciência pode dar resposta, para adquirir novos conhecimentos, explicar fenômenos científicos e tirar conclusões fundamentadas sobre problemas de caráter científico. Igualmente, a compreensão das características próprias da ciência como forma de investigação e conhecimento humano, a consciência do papel da ciência e da tecnologia na sociedade e na constituição do nosso meio material, intelectual e cultural, bem como a vontade de se envolver, enquanto cidadão consciente, em questões relacionadas com ciência e com o conhecimento científico, constituem elementos essenciais da definição de letramento científico.

0 Recommendation of the European Parliament and of the Council on key competences for lifelong learning (OJEU, 2006) reconhece igualmente o papel das competências basilares ao longo da vida para a construção participativa de um projeto político comum. A linguagem, a literacia, a competência matemática e as TIC constituem as ferramentas fundamentais e coextensivas aos processos de aprender e de aprender a aprender.

A articulação desejada entre a aprendizagem e a sociedade, instituindo um arco de aprendizagem ao longo da vida, encontra-se expressa no Memorando sobre Aprendizagem 
ao Longo da Vida, elaborado pela Comissão Europeia em 2000, em Lisboa (CCE, 2000, p. 11): "Novas competências básicas para todos e cujo objetivo é [...] garantir acesso universal e contínuo à aprendizagem, com vista à aquisição e renovação das competências necessárias à participação sustentada na sociedade do conhecimento.” É precisamente porque favorecem e potenciam a adequação de métodos e contextos de ensino e aprendizagem a uma grande diversidade de interesses, necessidades e exigências, não apenas de indivíduos, mas também de grupos de interesse específicos em sociedades europeias multiculturais, que as TIC adquirem relevo pedagógico: "As técnicas de aprendizagem assentes nas TIC oferecem amplas potencialidades de inovação nos métodos de ensino e de aprendizagem." (CCE, 2000, p. 15).

Em vários países, pelo menos em nível do ensino formal e obrigatório, a educação em ciência já é para todos. Isso remete-nos indubitavelmente para outra questão, que se deve colocar em nível da justificação social das finalidades educativas e, por isso mesmo, o "para quem" aparece intimamente articulado à questão do "para quê".

\section{Considerações finais}

Salientando a importância que as instituições educativas e os seus docentes apresentam na gestão do impacto das mudanças na sociedade, Toledo (2007) refere que, nessa avalanche de informação e virtualização das interações, os jovens necessitam, tanto ou mais do que nunca, estar perto de quem os oriente no processo de selecionar a informação relevante e de criar as ligações que façam sentido entre o que estava inicialmente disperso. Os professores e os pais são, portanto, interlocutores privilegiados na relação que os jovens estabelecem com as TIC. Para eles, orientação e mediação afıguram-se muito bem-vindas. Tal como sublinham Coutinho e Bottentuit (2006), é fundamental propor aos alunos abordagens multidisciplinares, mediadas pelas TIC, que os preparem para lidar com as incertezas de um mundo global em que a aprendizagem e o conhecimento são os melhores instrumentos para a inserção na sociedade. Nesse cenário, é crucial que a educação em ciência, e consequentemente o ensino das ciências, contribua para "problematizar o saber" e contextualizar os conhecimentos, de modo que os alunos possam apropriar-se deles e mobilizá-los convenientemente em diversas situações com as quais são confrontados. Como referem Squire e Jan (2007, p. 6), é crucial preparar os alunos "para pensar criticamente num mundo sempre em mudanças" e motivá-los para se envolverem na aprendizagem das ciências, uma vez que, tal como referem Lim et al. (2006), tal envolvimento potencia a busca ativa pelo conhecimento para, assim, satisfazer a curiosidade.

Assim, a educação em ciências, justamente na medida em que persegue ideais de cultura científica dos alunos, opõe-se a uma lógica de mera instrução científica. Promovendo o desenvolvimento pessoal dos alunos, a educação em ciências - que hoje implica a letramento digital - permite-lhes alcançar uma participação social esclarecida. 


\section{Referências}

ABREU, Manuel. Tarefa fechada e tarefa aberta: motivação, aprendizagem e acção. Coimbra: Imprensa da Universidade, 1999. AFONSO, Almerindo; ANTUNES, Fátima. Educação, cidadania e competitividade: algumas questões em torno de uma nova agenda teórica e política. Cadernos de Pesquisa, n. 113, p. 83-112. 2001. Disponível em: <http://www.scielo.br/pdf/cp/ n113/a05n113.pdf>. Acesso em: abr. 2013.

ALMEIDA, João. Inovação e atitude cultural. In: DEBATES PRESIDÊNCIA DA REPÚBLICA (Org.). Sociedade, tecnologia e inovação empresarial. Lisboa: Casa da Moeda, 2000. p. 34-35.

BAWDEN, David. Origins and concepts of digital literacy. In: LANKSHEAR, C.; KNOBEL, M. Digital literacies: concepts, policies and practice. New York: Peter Lang Publishing. 2008. p. 17-32. Disponível em: <http://www.soi.city.ac.uk/ dbawden/digital\%20 literacy\%20chapter.pdf>. Acesso em abr. 2013.

BENNETT, Sue; MATON, Karl; KERVIN, Lisa. The 'digital natives' debate: a critical review of the evidence. British Journal of Educational Technology, v. 39 n. 5, p. 775-786, 2008.

BARAJAS, Mário; SCHEUERMANN, Friedrich; KIIIS-PAPADAKIS, Kathy. Critical indicators of innovative practices em ICT supported learning. In: IMPROVING LEARNING THROUGH TECHNOLOGY: OPPORTUNITIES FOR ALL (PROMETEUS CONFERENCE), 2002, Paris.

BECTA - British Educational Communications and Technology Agency, 2006, Coventry. ICT and e-learning in further education: management, learning and improvement. A report on the further education sector's engagement with technology. Disponivel em: <http://publications.becta.org.uk/display.cfm?reslD=28534>. Acesso em: abr. 2013.

CACHAPUZ, António; et al. Saberes básicos de todos os cidadãos no Séc. XXI. Lisboa: Conselho Nacional de Educação, 2004.

CASTELLS, Manuel. A sociedade em rede. São Paulo: Paz e Terra, 1999. v. 1.

CASTELLS, Manuel. A galáxia da internet. Lisboa: Fundação Calouste Gulbenkian, 2004.

CCE - Comissão das Comunidades Europeias. MALV: Memorando sobre Aprendizagem ao Longo da Vida. Bruxelas, 2000. Disponível em: <http://dne.cnedu.pt/dmdocuments/Memorando\%20sobre\%20Aprendizagem\%20Longo\%20da\%20Vida\%20pt.pdf>. Acesso em: abr. 2013.

CHASSOT, Attico. Alfabetização científica: questões e desafios para a educação. ljui: Unijui, 2000.

COUTINHO, Clara; BOTTENTUIT, João. A complexidade e os modos de aprender na sociedade do conhecimento. In: COLÓQUIO DA SECÇÃO PORTUGUESA DA ASSOCIATION FRANCOPHONE INTERNATIONALE DE RECHERCHE SCIENTIFIQUE E EDUCATION, 14. 2008, Universidade de Lisboa. Disponível em: <http://repositorium.sdum.uminho.pt/bitstream/1822/6501/1/Afirse\%202007\%20 Final.pdf>. Acesso em: abr. 2013.

DAVIS, Niki; ROBLYER, Margaret. Preparing teachers for the "schools that technology built". Journal of Research on Technology in Education, ano 37, n. 4, p. 399-409, 2005.

DOLL Júnior. Currículo: uma perspectiva pós-moderna. Porto Alegre: Artes Médicas, 1998.

FIGUEIREDO, António. Redes de educação: a surpreendente riqueza de um conceito. In: CONSELHO NACIONAL DE EDUCAÇÃO (Org.) Redes de aprendizagem, redes de conhecimento. Lisboa: CNE, 2002. p. 39-55.

HENNESSY, Sara; RUTHVEN, Kenneth; BRINDLEY, Sue. Teacher perspectives on integrating ICT into subject teaching: commitment, constraints, caution, and change. Journal of Curriculum Studies, ano 37, n. 2, p. 155-192, 2005.

HODSON, Derek. Teaching and learning science. Buckingham: Open University Press, 1998.

HOHLFELD, Tina; RITZHAUPT, Albert; BARRON, Ann. Connecting schools, community, and family with ICT: Four-year trends related to school level and SES of public schools in Florida. Computers \& Education, v. 55, p. 391-405, 2010. 
JONASSEN, David. Computadores, ferramentas cognitivas: desenvolver o pensamento crítico nas escolas. Porto: Porto Editora, 2007.

INTERNATIONAL TELECOMMUNICATION UNION. Measuring information society. Geneva, 2013. Disponível em <http://www.itu. int/en/TU-D/Statistics/Documents/publications/mis2013/MIS2013_without_Annex_4.pdf >. Acesso em: abr. 2013.

KNOWLTON, Nancy. Children and education, class (room) and technologies. AEP - Association of Educational Publishers. 2007.

KOLIKANT, Yifat. Using ICT for school purposes: Is there a student school disconnect? Computers \& Education, v. 59, p. 907-914, 2012.

LEWIN, Cathy; LUCKIN, Rosemary. Technology to support parental engagement in elementary education: Lessons learned from the UK. Computers \& Education, v. 54, p. 749-758. 2010.

LEVIN, Douglas; ARAFEH, Sousan. The digital disconnect: the widening gap between Internet-savvy students and their schools. PEW Internet and American Life Project. 2002. Disponivel em: <www.pewlnternet.org/PPF/r/67/report_display.asp>. Acesso em: abr. 2013.

LÉVY, Pierre. Cibercultura. Lisboa: Instituto Piaget, 1997.

LÉVY, Pierre. A inteligência colectiva. Lisboa: Instituto Piaget, 1998.

Recebido em: 25.04.2013

Aprovado em: 11.12.2013

Carla Morais é Professora Auxiliar Convidada no Departamento de Química e Bioquímica (seção de Educação), da Faculdade de Ciências da Universidade do Porto, Portugal. É membro da Unidade de Ensino de Ciências dessa Faculdade e do Centro de Investigação em Química da Universidade do Porto (CIQUP).

João Paiva é Professor Auxiliar, com agregação, no Departamento de Química e Bioquímica (seção de Educação), da Faculdade de Ciências da Universidade do Porto, Portugal. É membro da Unidade de Ensino de Ciências dessa Faculdade e coordenador do grupo de Química e Sociedade no Centro de Investigação em Química da Universidade do Porto (CIQUP). 